\title{
$\$$ Research Square

\section{Characteristics, Decoupling Effect And Driving Factors of Regional Tourism's Carbon Emissions In China}

\section{Guobao Xiong}

East China University of Technology

Junhong Deng ( $\square$ dengjunhong_a@163.com )

East China University of Technology https://orcid.org/0000-0002-0174-0989

\section{Baogen Ding}

East China University of Technology

\section{Research Article}

Keywords: Tourism, Carbon emission, Decoupling effect, Factor decomposition, LMDI model, China

Posted Date: December 10th, 2021

DOI: https://doi.org/10.21203/rs.3.rs-1076229/v1

License: (c) (i) This work is licensed under a Creative Commons Attribution 4.0 International License. Read Full License

Version of Record: A version of this preprint was published at Environmental Science and Pollution Research on February 17th, 2022. See the published version at https://doi.org/10.1007/s11356-02219054-9. 
Characteristics, Decoupling Effect and Driving Factors of Regional Tourism's

Carbon Emissions in China

Guobao Xiong ${ }^{1,2} \cdot J^{\prime}$ unhong Deng ${ }^{1, *} \cdot$ Baogen Ding ${ }^{1}$

1 Resource and Environmental Economic Research Center, East China University of Technology, 330013 Nanchang, China;

2 Resources and Environmental Strategy Soft Science Research Base of Jiangxi, 330013 Nanchang, China

* Correspondence: dengjunhong a@163.com

Funding: This research was funded by National Social Science Foundation of China, grant number 19CJY040; Social science key research base project of Jiangxi province of 2021, grant number 21SKJD07

\begin{abstract}
Using the tourism's carbon emission data of 30 provinces (cities) in China from 2007 to 2019, we have established a logarithmic mean Divisia index (LMDI) model to identify the main driving factors of carbon emissions related to tourism and a Tapio decoupling model to analyze the decoupling relationship between tourism's carbon emissions and tourism-driven economic growth. Our analysis suggests that China's regional tourism's carbon emissions are growing significantly with marked differences across its regions. Although there are observed fluctuations in the decoupling relationship between regional tourism's carbon emissions and tourism-driven economic growth in China, the data suggest weak decoupling. Nonetheless, the degree of decoupling is rising to various extents across regions. Three of the five driving factors investigated are also found to affect on emissions. Both tourism scale and tourism consumption lead to the growth of tourism's carbon emissions, while energy intensity has a significant effect on reducing emissions. These effects differ across regions.

Key words Tourism · Carbon emission · Decoupling effect · Factor decomposition · LMDI model $\cdot$ China

\section{Introduction}

The rise in carbon emissions is a major contributor to global climate change. It is expected that global tourism's carbon emissions will continue to grow at a rate of $2.5 \%$ per year until 2035 (Castellani et al. 2010). As one of the most resilient economic sectors in the world, tourism also exacerbates environmental pressure. Statistics show that this sector has contributed $8 \%$ to the total global greenhouse gas emissions in 2013. As a major contributor to the world economy, China occupies a pivotal position in the global tourism market. In 2019, China's tourism revenue reached 6.63 trillion-yuan, accounting for $11.05 \%$ of its GDP. The resulting energy consumption and the carbon emissions generated to meet the needs of tourists, however, cannot be ignored. Due to this presence, China naturally becomes an integral part of achieving global carbon reduction targets. Low-carbon developments within China's tourism industry are not only instrumental for achieving high-quality economic development, but also an inevitable path for China as it seeks to achieve the goals of "carbon peak" and "carbon neutrality". To realize these goals, it will be imperative to have a better understanding of the driving factors of tourism's carbon emissions in China, and how these factors impact tourism-driven economic growth.
\end{abstract}


Based on the above background, this paper uses the bottom-up method to measure the carbon emissions of tourism in 30 provinces (cities) in China from 2007 to 2019. The LMDI model is introduced to identify the main driving factors of tourism's carbon emissions and the Tapio decoupling model is applied to analyze the decoupling relationship between tourism's carbon emissions and tourism-driven economic growth. Its finding will have implications on the development of more targeted emission reduction measures for tourism in China and promote the low-carbon and high-quality economic development of China's tourism industry.

\section{Literature Review}

The literature on tourism's carbon emissions can be traced back to the preliminary studies of Annika (1999) and Schafer et al. (1999) on energy consumption and carbon emissions generated in tourism. The last two decades have seen more in-depth research on this field, with more sophisticated research methods being utilized and an expansion in the research scope.

In terms of research methods adopted in the literature, the two mainstream measurements of carbon emissions are the top-down method and the bottom-up method (Gössling et al. 2004). For example, Cheng (2020) and Liu et al. (2019) have applied these methods to estimate China's tourism-related carbon emissions. Based on the concept of "tourism consumption stripping coefficient", Xie et al. (2012) constructed a set of measurement methods that were consistent with China's statistical standards. And Zhao et al. (2018), based on the input-output method, explored the impacts of productions of various sub-sectors of tourism on carbon emissions.

In terms of research content, Huang (2019) and Tian et al. (2018) focused on the spatial-temporal pattern and characteristics of tourism's carbon emissions in the Yangtze River Economic Belt and Shandong province. Wang et al. (2018) evaluated the efficiency of tourism's carbon emissions, and then Wang et al. (2019) explored the spatial correlation between tourism industry aggregation and carbon emissions. Based on the Tapio decoupling model, Huang (2021) and Hu et al. (2019) analyzed the decoupling of tourism's carbon emissions in the Yellow River Basin and Tibet region and unraveled spatial pattern characteristics. Zha (2018), Weng (2021) and Sun et al. (2020) analyzed the factors influencing the change of tourism's carbon emissions by using the exponential decomposition method. And it was found that energy intensity, energy structure, tourism added value, tourism scale, sector structure, and technology effect are the key factors that increase or limit tourism's carbon emissions.

To sum up, research on tourism's carbon emissions in recent years mainly focuses on (1) the driving factors of tourism's carbon emissions, (2) the measurement and effect of tourism's carbon emissions, (3) the temporal and spatial variation characteristics of tourism's carbon emissions, and (4) the decoupling relationship between tourism's carbon emissions and economic growth.

The advancement of research in this field has laid a strong foundation for the study of tourism's carbon emissions in China. However, comprehensive and systematic studies across regions in China remain scarce. Furthermore, the analysis of characteristics of decoupling and the influence of different factors on the decoupling index across time are not in-depth. The focus should also be put on the impact of different factors at the provincial levels rather than the China tourism market as a whole. This paper will address these research gaps by using a decoupling model and LMDI method to carry out a systematic study on China's regional tourism's carbon emissions.

\section{Methods and Data}

\subsection{Data Collection}

This study uses panel data from 30 provinces in China in the period from 2007 to 2019. Data of Hong Kong, Macao, Taiwan and Tibet are excluded due to missing observations. Statistics on the 
number of Chinese and foreign tourists, tourism income, passenger turnover of all means of traffic come from China Statistical Yearbooks, the statistical yearbooks and bulletins of each province; the number of beds and rental rate of star-rated hotels come from China Tourism Statistical Yearbook, China Tourism Statistical Bulletin, China Urban Statistical Yearbook; the proportion of tourists participating in various tourism activities comes from the Sample Survey Report of Inbound Tourists and Sample Survey Report of Domestic Tourists.

\subsection{Methods}

\subsubsection{Estimation of Tourism's Carbon Emissions and Energy Consumption}

Due to the relative lack of tourism data, this paper will use the bottom-up method to estimate tourism's carbon emissions in China using various proxies. Based on the existing literature, three key areas of tourism's carbon emissions are identified, namely tourism transportation, tourism activities and tourism accommodation. In this study, carbon emissions and energy consumption of tourism will be constructed through a composite measure consisting of these three components. The formulas are as follows:

$$
\mathrm{C}=C_{1}+C_{2}+C_{3}
$$

Where $C$ is the total carbon emissions and energy consumption of tourism; $C_{1}, C_{2}$, and $C_{3}$ are respectively the carbon emission and energy consumption of tourism transportation, tourism accommodation, and tourism activities.

$$
C_{1}=\sum_{i=1}^{30} \sum_{j=1}^{4} R_{x i}^{t} \cdot f_{x} \cdot \alpha_{x}
$$

Where $C_{l}$ is the total carbon emissions/energy consumption of tourism transportation; $\mathrm{x}$ represents four modes of transportation, namely railway, highway, air, and water transportation; $R_{x i}^{t}$ is the passenger turnover of various modes of transportation in each province; $\alpha_{x}$ denotes the carbon emissions and energy consumption coefficient of type $\mathrm{x}$ transportation modes; $f_{x}$ represents the proportion of tourists in all types of passenger traffic. According to the actual situation of China's tourism industry and the existing research results, the carbon emissions coefficient of railway, highway, air, and water transportation is $27 \mathrm{gCO}_{2} / \mathrm{pkm}, 133 \mathrm{gCO}_{2} / \mathrm{pkm}, 137 \mathrm{gCO}_{2} / \mathrm{pkm}, 106 \mathrm{gCO}_{2} / \mathrm{pkm}$, and the energy consumption coefficient is $1 \mathrm{MJ} / \mathrm{pkm}, 1.8 \mathrm{MJ} / \mathrm{pkm}, 2 \mathrm{MJ} / \mathrm{pkm}, 0.9 \mathrm{MJ} / \mathrm{pkm}$ respectively (Nae-Wen Kuo et al. 2009; Shi Peihua et al. 2011); the tourist proportion of railway, highway, air, and water transportation is $31.6 \%, 13.8 \%, 64.7 \%$, and $10.6 \%$ respectively (Wei Yanxu et al. 2012).

$$
C_{2}=\sum_{i=1}^{30} N_{i}^{t} \cdot l_{i}^{t} \cdot \delta \cdot n
$$

Where $C_{2}$ is the total carbon emission and energy consumption of tourism accommodation; $N_{i}^{t}$ is the number of beds in star-rated hotels in each province; $l_{i}^{t}$ is the average room occupancy rate of each province; $\delta$ represents the carbon emission/energy consumption coefficient per bed per night, the carbon emission coefficient was 2.458 , the energy consumption coefficient is $155 \mathrm{MJ}$ per bed per night (Shi Peihua et al. 2011); $n$ is the number of days the hotel operates, which is set to 365 days.

$$
C_{3}=\sum_{i=1}^{30} \sum_{m=1}^{5} Q_{i m}^{t} \cdot \gamma_{m}
$$

Where $C_{3}$ is the total carbon emissions and energy consumption of tourism activities; $\mathrm{m}$ refers to five types of tourism activities, namely leisure vacation, sightseeing, business trip, visiting relatives and friends, etc.; $Q_{i m}^{t}$ is the number of tourists participating in various activities in each province; $\gamma_{m}$ is the carbon emissions and energy consumption coefficient of various tourism activities. According to research (Shi Peihua et al. 2011), the carbon emission coefficient of the above-mentioned activities is $1670 \mathrm{gCO}_{2} /$ per, $417 \mathrm{gCO}_{2} /$ per, $786 \mathrm{gCO}_{2} /$ per, $591 \mathrm{gCO}_{2} /$ per, $172 \mathrm{gCO}_{2} /$ per, and the energy consumption coefficient is $26.5 \mathrm{MJ} /$ per, $8.5 \mathrm{MJ} /$ per, $16 \mathrm{MJ} /$ per, $12 \mathrm{MJ} /$ per and $3.5 \mathrm{MJ} /$ per respectively. 
The concept of "decoupling" was first proposed in the 1960s and has been widely used in agricultural policy, economics, and other research fields. According to the value of decoupling elasticity, the decoupling state can be divided into eight types, as shown in Table 1.

Table 1 Decoupling state type

\begin{tabular}{|c|c|c|c|c|}
\hline \multicolumn{2}{|c|}{ Decoupling State } & $\Delta \mathrm{C} / \mathrm{C}$ & $\Delta \mathrm{G} / \mathrm{G}$ & Elasticity e \\
\hline \multirow{3}{*}{ Negative decoupling } & Expansion negative decoupling & + & + & $\mathrm{e}>1.2$ \\
\hline & Strong negative decoupling & + & - & $\mathrm{e}<0$ \\
\hline & Weak negative decoupling & - & - & $0 \leq \mathrm{e}<0.8$ \\
\hline \multirow{3}{*}{ Decoupling } & Weak decoupling & + & + & $0 \leq \mathrm{e}<0.8$ \\
\hline & Strong decoupling & - & + & $\mathrm{e}<0$ \\
\hline & Recession decoupling & - & - & $\mathrm{e}>1.2$ \\
\hline \multirow{2}{*}{ Connection } & Expansive coupling & + & + & $0.8 \leq \mathrm{e}<1.2$ \\
\hline & Recessive coupling & - & - & $0.8 \leq \mathrm{e}<1.2$ \\
\hline
\end{tabular}

Based on the Tapio model, this paper analyzes the decoupling relations between regional tourism's carbon emissions and tourism-driven economic growth in China. The formula is as follows:

$$
\mathrm{e}=\frac{\Delta C / C}{\Delta G / G}
$$

Where $E$ is the elasticity of decoupling; $C$ is tourism's carbon emissions; $\Delta C$ is the change in carbon emissions; $G$ is the tourism-driven economic growth, expressed in tourism revenue; $\Delta G$ is the change in tourism-driven economic growth.

\subsubsection{Factor Decomposition of Tourism's Carbon Emissions}

Decomposition analysis is widely used in economic and social research fields, which allows time series analysis and cross-regional comparisons simultaneously. Dee's exponential decomposition method, in particular, has been increasingly used (Alajmi 2021; Lisaba et al. 2021). This paper adopts the LMDI method (Ang et al. 1994) to analyze the driving factors of tourism's carbon emissions.

Based on Kaya identity, the LMDI multi-dimensional factor decomposition model is shown as follows:

$$
\mathrm{C}=\frac{C}{E} \times \frac{E}{G} \times \frac{G}{P} \times \frac{P}{S} \times S=\beta_{0} \times \beta_{1} \times \beta_{2} \times \beta_{3} \times \beta_{4}
$$

Where $C$ is the carbon emission of tourism; $\mathrm{E}$ is the energy consumption of tourism; $G$ is the tourism revenue; $P$ is the number of tourists; $S$ is the total population of the region; $\beta_{0}$ is the carbon emission coefficient factor of tourism, expressed as the ratio of tourism's carbon emissions to energy consumption; $\beta_{1}$ is the tourism energy intensity factor, expressed in energy consumption per unit of tourism income; $\beta_{2}$ is the tourism consumption level factor, expressed in per capita tourism consumption; $\beta_{3}$ is the tourism scale factor, expressed by the ratio of tourist numbers to the total population; $\beta_{4}$ is the regional population factor, expressed by the total population of the region.

Using the LMDI additive decomposition approach, tourism's carbon emission increment $C$ can be decomposed into the sum of carbon emission coefficient effect $\left(\Delta \beta_{0}\right)$, tourism energy intensity effect $\left(\Delta \beta_{l}\right)$, tourism consumption level effect $\left(\Delta \beta_{2}\right)$, tourism scale effect $\left(\Delta \beta_{3}\right)$ and regional population effect $\left(\Delta \beta_{4}\right)$.

$$
\Delta \mathrm{C}=\Delta \beta_{0}+\Delta \beta_{1}+\Delta \beta_{2}+\Delta \beta_{3}+\Delta \beta_{4}
$$

In addition, according to the formula of the Tapio decoupling model, the decoupling index of 
tourism's carbon emissions and tourism-driven economic growth can be decomposed into:

$$
\mathrm{e}=\Delta \mathrm{C} \times \frac{G}{C \times \Delta G}=\left(\Delta \beta_{0}+\Delta \beta_{1}+\Delta \beta_{2}+\Delta \beta_{3}+\Delta \beta_{4}\right) \times \frac{G}{C \times \Delta G}=\frac{\Delta \beta_{0} \times G}{C \times \Delta G}+\frac{\Delta \beta_{1} \times G}{C \times \Delta G}+\frac{\Delta \beta_{2} \times G}{C \times \Delta G}+\frac{\Delta \beta_{3} \times G}{C \times \Delta G}+
$$

$$
\frac{\Delta \beta_{4} \times G}{C \times \Delta G}=\varepsilon_{0}+\varepsilon_{1}+\varepsilon_{2}+\varepsilon_{3}+\varepsilon_{4}
$$

Where $\varepsilon_{0}$ is the decoupling index of tourism's carbon emission coefficient; $\varepsilon_{l}$ is the decoupling index of tourism energy intensity; $\varepsilon_{2}$ is the decoupling index of tourism consumption level; $\varepsilon_{3}$ is the index of tourism scale decoupling; $\varepsilon_{4}$ is the index of regional population decoupling. Due to space limitations, the specific decomposition process is not described here.

\section{Results}

\subsection{Analysis on the Carbon Emission Situation of China's Regional Tourism Industry}

\subsubsection{Timing Difference in China's Regional Tourism Carbon Emissions}

Based on formulas (1) to (4), the carbon emissions of China's regional tourism and its various sectors are calculated (see Figure 1). As the figure suggests, the carbon emissions of tourism in 2019 is 179.31 million tons, 2.7 times over the 2007 figures, constituting an average annual growth rate of $9.15 \%$. The carbon emissions caused by tourism transportation, tourism accommodation, and tourism activities account for $87.69 \%, 5.65 \%$, and $6.66 \%$ of the total tourism's carbon emissions respectively. From 2007 to 2019, the total carbon emissions of China's regional tourism industry have also been on the rise, as the tourism industry has promoted the development of related industries, intensifying $\mathrm{CO}_{2}$ emissions. Tourism transportation accounts for $72 \%$ to $88 \%$ of carbon emissions in the tourism industry across the studied period. Due to this dominant presence, the focus of tourism's carbon emission reduction will likely be focused on tourism transportation in the future. The overall carbon emission of tourism accommodation, however, demonstrates a fluctuating downward trend, accounting for $24.4 \%$ at its peak. This is not surprising as there is an increasing acceptance of energy-saving and emission reduction measures in accommodation facilities and an increasing tendency of large-scale operation of the tourism accommodation industry, bringing advances in the efforts of controlling carbon emissions. Tourism activities account for the smallest proportion of carbon emissions and show a fluctuating upward trend during the studied period. This is probably due to the differences in consumption and travel purpose of tourists in different periods. Overall, the factor input and carbon emissions of tourism activities are increasing year by year, suggesting that the environmental problems caused by tourism activities need greater attention.
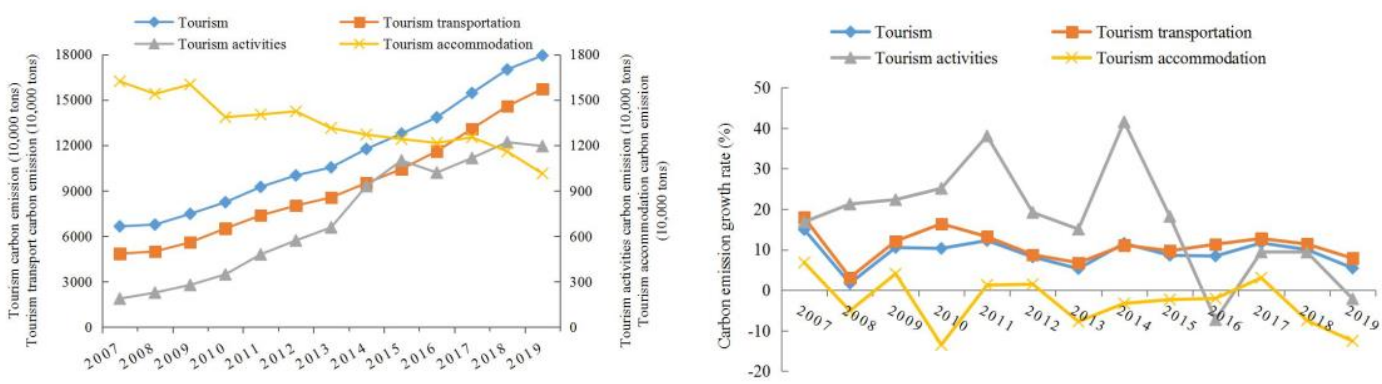

Fig.1 Total carbon emissions of regional tourism and various sectors in China from 2007 to 2019

\subsubsection{Spatial Difference in China's Regional Tourism's Carbon Emissions}

As can be seen from Figure 2, there are significant differences in tourism's carbon emissions among China's provinces in the year 2019. Among them, tourism's carbon emissions of Guangdong (26.43 million tons), Shanghai (21.53 million tons) and Beijing (19.15 million tons) are much higher 
than other provinces. Together, they account for $37.42 \%$ of the national tourism's carbon emissions. Qinghai has the lowest carbon emissions of 0.73 million tons, equivalent to $0.4 \%$ of the nation's total. Carbon emissions in the eastern and western regions account for $89.62 \%$ of the total. The high concentration of carbon emissions in these regions is expected as provinces in eastern China are more economically developed while provinces in western China have become attractive tourist destinations due to their enhanced infrastructure and investment in tourism. However, it's shown that the central region has the highest carbon emission intensity, followed by the western region and finally the eastern region. There are also wide-ranging differences among the provinces. For example, Jiangxi has the highest carbon emission intensity of 42.1 tons per 10,000 yuan, while Hainan has the lowest carbon emission intensity of only 1.3 tons per 10,000 yuan.

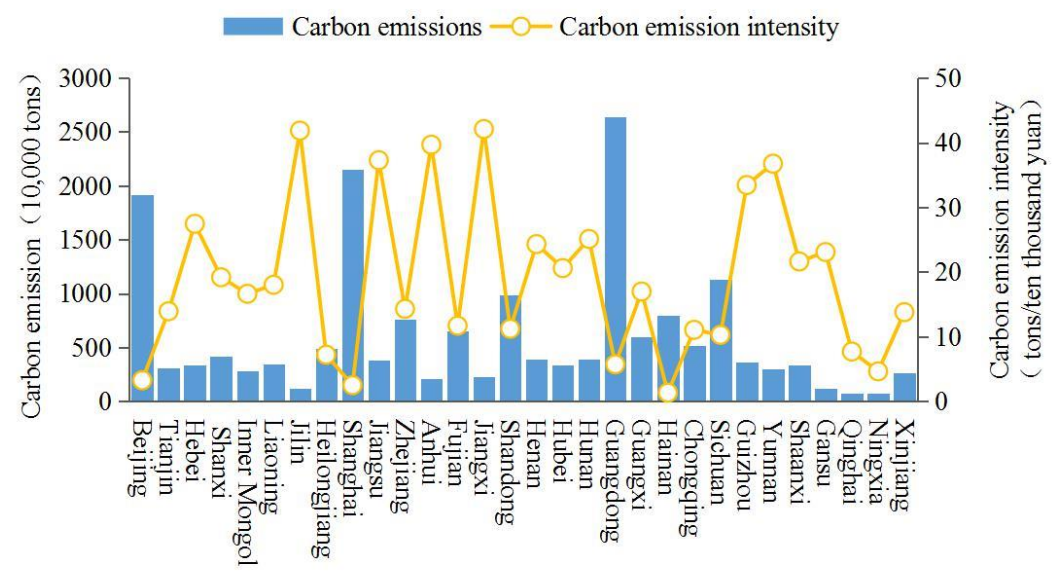

Fig.2 Carbon emissions and carbon intensity of tourism in 30 provinces (cities) in China in 2019

\subsection{Decoupling Effect and Driving Factors of China's Regional Tourism's Carbon Emissions}

\subsubsection{Temporal and Spatial Characteristics of Carbon Emission Decoupling in China's Regional} Tourism Industry

Based on the Tapio decoupling model, the carbon emission decoupling index and its temporal changes in China's regional tourism industry from 2007 to 2019 can be calculated, as shown in Table 2. As can be seen, the decoupling index of the regional tourism's carbon emissions fluctuates across the studied period, with the highest being 0.698 and the lowest at -1.606 . The key driving factors of the decoupling elasticity, tourism consumption level, tourism scale, and regional population elasticity all have positive effects on the decoupling index of tourism's carbon emissions. In addition, the tourism consumption level and tourism scale elasticity are higher than the decoupling elasticity of tourism's carbon emissions during the studied period, indicating that these two are the main factors affecting the decoupling state. The overall elasticity of energy intensity and tourism's carbon emission coefficient is negative, playing an important role in curbing tourism's carbon emissions. Overall, tourism's carbon emissions were experiencing weak decoupling. The strong negative decoupling in 2009 was mainly caused by the rapid decline of the tourism industry in these two years.

Table 2 Decoupling characteristics and driving factors decoupling elastic changes of regional tourism carbon emissions in China from 2007 to 2019

Year $\Delta \mathrm{C} / \mathrm{C} \quad \Delta \mathrm{G} / \mathrm{G} \quad \mathrm{e} \quad \begin{gathered}\text { Decoupling } \\ \text { characteristics }\end{gathered} \Delta \beta_{0}$ Elasticity $\quad \Delta \beta_{1}$ Elasticity $\quad \Delta \beta_{2}$ Elasticity $\quad \Delta \beta_{3}$ Elasticity $\quad \Delta \beta_{4}$ Elasticity




\begin{tabular}{|c|c|c|c|c|c|c|c|c|c|}
\hline 2007 & 0.150 & 0.223 & 0.670 & $\begin{array}{c}\text { Weak } \\
\text { decoupling }\end{array}$ & -0.000 & -0.062 & 0.044 & 2.468 & 0.008 \\
\hline 2008 & 0.017 & 0.464 & 0.037 & $\begin{array}{c}\text { Weak } \\
\text { decoupling }\end{array}$ & -0.027 & -0.338 & 0.245 & 0.129 & 0.008 \\
\hline 2009 & 0.105 & -0.066 & -1.606 & $\begin{array}{c}\text { Strong } \\
\text { negative } \\
\text { decoupling }\end{array}$ & -0.007 & 0.161 & -0.263 & 0.188 & 0.007 \\
\hline 2010 & 0.103 & 0.251 & 0.411 & $\begin{array}{c}\text { Weak } \\
\text { decoupling }\end{array}$ & -0.024 & -0.102 & 0.052 & 0.165 & 0.005 \\
\hline 2011 & 0.122 & 0.251 & 0.488 & $\begin{array}{c}\text { Weak } \\
\text { decoupling }\end{array}$ & -0.005 & -0.103 & 0.002 & 0.217 & 0.006 \\
\hline 2012 & 0.082 & 0.256 & 0.321 & $\begin{array}{c}\text { Weak } \\
\text { decoupling }\end{array}$ & -0.002 & -0.147 & 0.142 & 0.080 & 0.005 \\
\hline 2013 & 0.053 & 0.158 & 0.336 & $\begin{array}{c}\text { Weak } \\
\text { decoupling }\end{array}$ & 0.066 & -0.162 & -0.040 & 0.182 & 0.005 \\
\hline 2014 & 0.113 & 0.162 & 0.698 & $\begin{array}{c}\text { Weak } \\
\text { decoupling }\end{array}$ & -0.001 & -0.038 & -0.005 & 0.150 & 0.006 \\
\hline 2015 & 0.086 & 0.160 & 0.537 & $\begin{array}{c}\text { Weak } \\
\text { decoupling }\end{array}$ & 0.019 & -0.085 & 0.035 & 0.107 & 0.006 \\
\hline 2016 & 0.085 & 0.177 & 0.478 & $\begin{array}{c}\text { Weak } \\
\text { decoupling }\end{array}$ & 0.008 & -0.090 & 0.017 & 0.140 & -0.001 \\
\hline 2017 & 0.117 & 0.223 & 0.523 & $\begin{array}{c}\text { Weak } \\
\text { decoupling }\end{array}$ & 0.011 & -0.102 & 0.046 & 0.156 & 0.013 \\
\hline 2018 & 0.100 & 0.190 & 0.530 & $\begin{array}{c}\text { Weak } \\
\text { decoupling }\end{array}$ & 0.007 & -0.085 & 0.039 & 0.122 & 0.005 \\
\hline 2019 & 0.054 & 0.173 & 0.315 & $\begin{array}{c}\text { Weak } \\
\text { decoupling }\end{array}$ & 0.001 & -0.107 & 0.031 & 0.123 & 0.008 \\
\hline
\end{tabular}

To further illustrate the differences of tourism's carbon emission decoupling effect across regions, we dissected the research period into three sub-stages: 2007-2010, 2010-2015, and 2015-2019, with a view to exploring the changing characteristics of tourism's carbon emission decoupling types during the $11^{\text {th }}, 12^{\text {th }}$, and $13^{\text {th }}$ Five-Year Plans in China. According to the experience of developed countries, the decoupling index generally goes through a process of "strong decoupling - weak decoupling negative decoupling - strong decoupling" (Tang 2015). However, it can be observed that most provinces in China were still in a weak decoupling state from 2007 to 2019.

(1) From 2007 to 2010, only Hebei, Jiangsu, Sichuan, and Yunnan showed strong decoupling, accounting for $13.3 \%$ of the total. This indicates that tourism's carbon emissions and tourism-driven economy in these regions have gradually stepped into the coupling stage. Beijing was in the state of expansive coupling, while other provinces were in a weak decoupling state. Among all provinces, Jiangsu had the highest degree of decoupling, while Beijing had the lowest, with the decoupling elasticity indexes of -0.173 and 1.033 respectively.

(2) From 2010 to 2015, the provinces with strong decoupling states in the previous stage all transitioned to weak decoupling states. Tianjin, Liaoning, and Shanghai all showed expansive negative decoupling, while Chongqing showed growth and connection. Among all provinces, the highest degree of decoupling was in Xinjiang, and the lowest was in Chongqing, with a decoupling index of 0.112 and 
0.838 respectively.

(3) From 2015 to 2019, only Jilin showed strong decoupling, and its degree of decoupling was the highest, with a decoupling index of -0.007. Beijing, Shanghai, and Shandong showed expansive coupling, while Guangdong turned from a weak decoupling to an expansive negative decoupling, and its degree of decoupling was the lowest, with a decoupling index of 1.243. The remaining provinces were in a weak decoupling state.

\subsubsection{Decomposition of Driving Factors of Regional Tourism's Carbon Emissions in China}

Across the country, the tourism scale effect is the main driver of the increasing emissions in tourism. Over the studied period, the figure has increased from 35.67 million tons to 82.08 million tons. The scale of tourism reflects the development level of tourism, and the negative impact on the environment is increasingly evident. Tourism consumption level is closely related to the tourism scale. It can be seen from Figure 3 that the tourism consumption level effect also has an increasing influence on the change of tourism's carbon emissions, mainly because the increase of per capita consumption level makes people more likely to travel and consume. On the other hand, energy intensity has a significant negative effect on tourism's carbon emissions, with the cumulative change value moving from -20.67 million tons to -58.44 million tons. These observations suggest that the structure of tourism is constantly adjusted and optimized, and the energy efficiency is becoming more manageable. Regional population effect and carbon emission coefficient effect are found to have little effect on the change of tourism's carbon emissions, and similar trends are expected in the future.

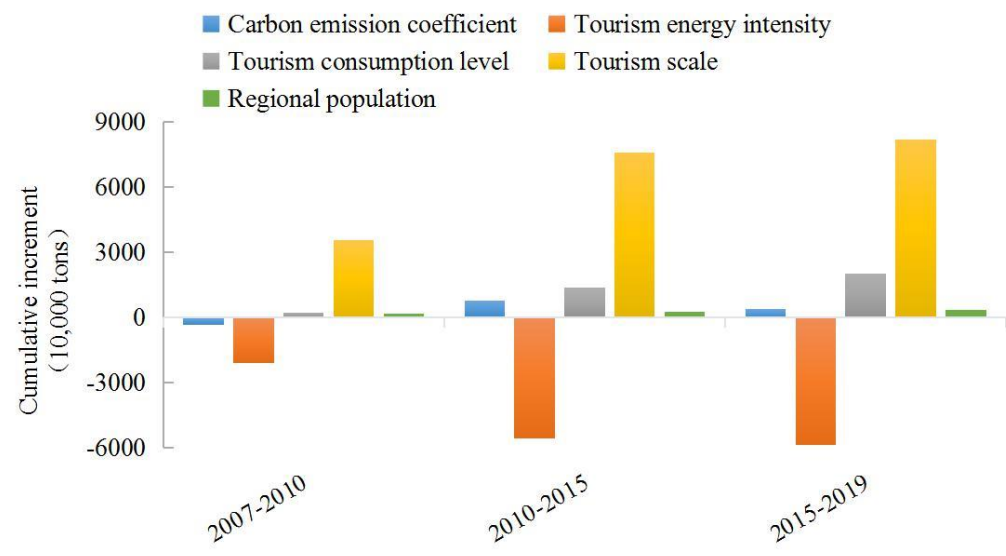

Fig.3 Effect decomposition of regional tourism carbon emission change in China from 2007 to 2019

To explore the differences in the effects of different factors in various provinces, the decomposition effects of tourism's carbon emission drivers at different periods in 30 provinces (cities) in mainland China were compared. This is shown in Figure 4. Analysis shows that:

(1) From 2007 to 2010, the regional tourism's carbon emissions in China increased by 15.94 million tons, of which Guangdong alone contributed 3.20 million tons, followed by Shanghai and Beijing. The key factor of the increased emissions in Guangdong was the tourism scale, while the main factors of the reduced emissions were tourism consumption level and energy consumption intensity. The regional population effect was a major contributor to the increase in tourism in Beijing. In Shanxi, the contribution value of tourism consumption level effect was negative, counteracting the positive effect of tourism scale. Tourism scale and energy intensity were the main factors that affected the carbon emissions of tourism in other provinces.

(2) From 2010 to 2015, regional tourism's carbon emissions in China increased by 45.27 million 
tons. Guangdong's tourism's carbon emission increment continued to be at a high level, followed by Sichuan, Beijing, and Shanghai. The tourism consumption level effect strengthened, and the energy intensity had a significant negative effect on carbon emission. The decomposition effect of tourism's carbon emissions in Shanxi experienced significant changes compared to the previous period. The tourism consumption level effect and tourism scale effect, however, changed in the opposite direction. In other provinces, while the effect of each driver on tourism's carbon emissions had changed to some extent, the changing directions were similar to the previous stage.

(3) From 2015 to 2019, the growth rate of regional tourism's carbon emissions in China slowed down, with an increment of 51.61 million tons. The highest increments came from Shanghai and Guangdong, reaching 7.76 and 7.46 million tons respectively. The effects of tourism scale and tourism consumption level on tourism's carbon emission growth in Shanghai had strengthened, while the energy intensity effect on the tourism's carbon emissions in Guangdong had decreased significantly. At this stage, the level of tourism-related consumption played a certain role in promoting the growth of tourism's carbon emissions in Shanxi province, and the inhibiting effect of energy intensity on tourism's carbon emissions in this province had gradually strengthened.

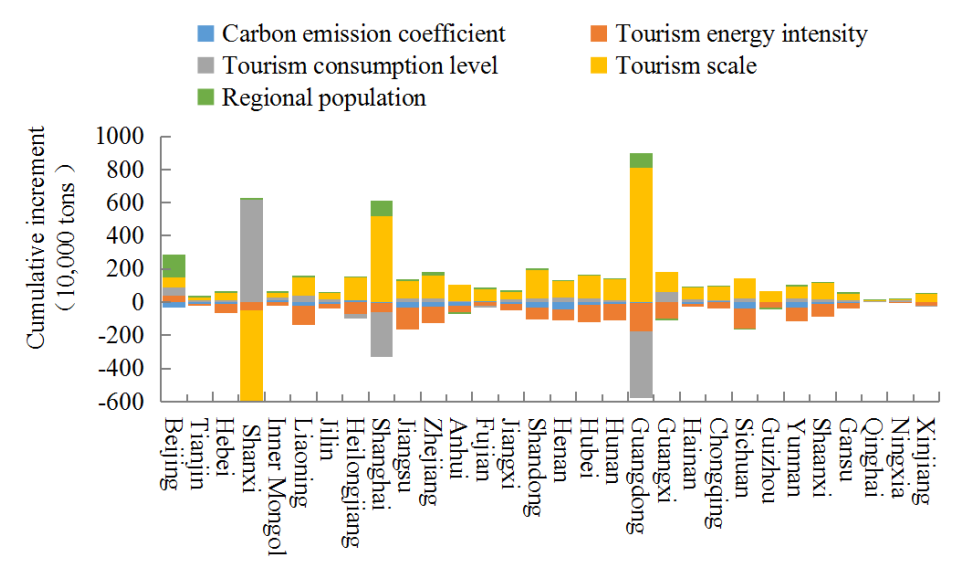

(a) $2007 \sim 2010$

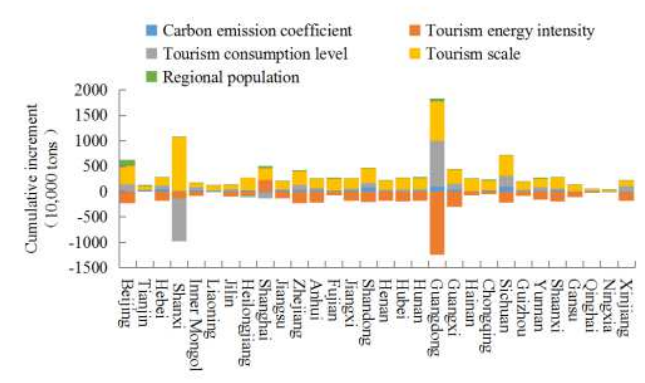

(b) 2010 2015

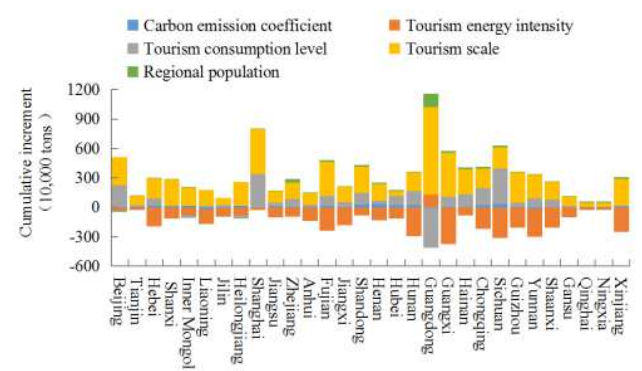

(c) $2015 \sim 2019$

Fig.4 Decomposition of tourism's carbon emission drivers in 30 provinces (cities) in China from 2007 to 2019

\section{Conclusions and Implications}

\subsection{Conclusion}

Like other traditional industries, China's tourism industry has experienced extensive development and brought about irreversible damages to the ecological environment. Due to the different resource endowments, economic and technological development levels across the regions of China, the extent of tourism's carbon emissions also differs to some extent. 
Regional tourism's carbon emissions in China are on the rise, with a large growth rate of $9.13 \%$ in our studied period. Tourism transportation is found to be the main source of tourism's carbon emissions. Further, there are significant regional differences observed - some economically developed provinces in eastern China and traditional tourism provinces in western China have much higher carbon emissions from tourism than other provinces. Regional tourism's carbon emission intensity of China is found to be highest in the central region, followed by the western region and finally the eastern region.

Although there are some fluctuations in the decoupling relationship between regional tourism's carbon emissions and tourism-driven economic growth in China, the overall observation is still weak decoupling. Tourism consumption level, tourism scale and regional population play positive roles in increasing the tourism's carbon emission decoupling index. The decoupling state of tourism's carbon emissions at different stages of each province is also found to be quite different.

We also find that carbon emission coefficient, energy intensity, tourism consumption level, tourism scale, and regional population affect the change of tourism's carbon emissions to varying degrees. Tourism consumption level and tourism scale are the main driving factors of tourism's carbon emission growth. Energy intensity has the most significant effect on tourism's carbon emission reduction, while the regional population effect and the carbon emission coefficient effect are found to have relatively little impact on the change in tourism's carbon emissions. Significant differences were observed among provinces, especially in Beijing, Shanxi, Shanghai, and Guangdong.

Our study has two limitations. First, due to limited data access, the analysis is only conducted at the provincial level. In the future, with the possibility of data access, we can further analyze at the county and city levels to go deeper to identify the drivers and possible ways of reducing tourism's carbon emissions across China. Second, the content and influencing factors of tourism's carbon emissions are by no means comprehensive in this study. Although the tourism's carbon emission measurement already includes the main areas of the tourism industry, its carbon emissions, and influencing factors are far greater than what we have covered and potentially even more complex at different levels of analysis within tourism. Nonetheless, we believe we have covered the key factors identified in the literature and thus provide a parsimonious model here. Future research should consider a wider range of aspects of the tourism industry for such investigation.

\subsection{Implications}

Tourism is not a smoke-free industry, and tourism's carbon emissions in China have not yet reached their peak. To achieve the leap from a weak decoupling to a strong decoupling, effective policy measures and joint efforts from multiple parties are needed. Therefore, it is necessary to consider the actual development of tourism in each province and chart the optimal path of low-carbon tourism development according to local conditions.

Optimizing the structure of the tourism industry will provide strong support to achieve low-carbon development for the industry. In recent years, the total carbon emissions of regional tourism in China have increased rapidly. To prevent the aggravation of environmental problems, we must pay attention to the optimization of the layout of tourism. All regions should focus on energy conservation and emissions reduction. Particular attention should be paid to provinces with high total and intensity of tourism's carbon emissions. For example, in the eastern region, Beijing, Shanghai, and Guangdong are the key provinces to focus on carbon emission reduction. Low-carbon tourism economic development should be regarded as an important condition. In western China, tourism's carbon emission reduction is mainly concentrated in Sichuan, Chongqing, Guizhou, and other traditional tourism provinces. For these provinces, the structure of tourism and related industries can be optimized accordingly to the 
different resource endowments and regional development levels. The central region should improve the utilization efficiency of tourism resources while promoting large-scale and high-quality tourism development.

Accelerating the adjustment of energy structure is the key to realizing the low-carbon development of tourism, as energy intensity has a significant inhibitory effect on tourism's carbon emissions. Creating a clean and efficient environment and improving the efficiency of energy use is crucial to the low-carbon development of the tourism industry. As an important field of energy conservation and emission reduction in tourism, the energy utilization efficiency of passenger transport cannot be ignored. All regions should actively promote the development of low-carbon transportation by reforming the mode of tourism transportation and increasing the use of clean energy vehicles. For the tourism accommodation industry, it is necessary to reduce energy consumption by upgrading energy-saving and emission reduction technologies and strengthening the management of the low-carbon accommodation industry. Finally, tourists should be educated to adopt a low-carbon tourism mentality, including guiding them towards low-carbon travel, green consumption, and other behaviors.

Coordinating regional tourism economic development is an important way to achieve low-carbon tourism development. The low-carbon and high-quality development of tourism cannot be achieved only with the efforts of one province. As there are significant differences in resource distribution and economic development across the provinces, it is particularly important to strengthen cooperation between provinces in the lead-up towards low-carbon tourism development. For example, some provinces with higher tourism development levels in the eastern region can provide leadership to the surrounding provinces using their economic and technological advantages. Provinces in the central region, such as Anhui, Jiangxi, and Hubei, can make use of the policy advantages of the Yangtze River Economic Belt to build a regional tourism economic circle and formulate two-way tourism emission reduction measures. The western region can jointly build a characteristic tourism demonstration area through regional characteristics and advantages to make up for the adverse impacts of distance, transportation, and other factors on tourism development. In addition, attention should be paid to the coordination and cooperation within provinces to achieve an overall high-quality tourism development.

Author contribution All the authors contributed to the study conception and design. Data analysis and writing were carried out by Junhong Deng. The reviewing, editing, and supervision were carried out by Guobao Xiong. Theory and method guidance were carried out by Baogen Ding.

Availability of data and material Original data are available from the corresponding author on reasonable request.

\section{Declarations}

Ethics approval Not applicable.

Consent to participate Not applicable.

Consent for publication Not applicable.

Competing interests The authors declare no competing interests. 
391 


\section{References}

Alajmi RG (2021) Factors that impact greenhouse gas emissions in Saudi Arabia: Decomposition analysis using LMDI. Energy Policy 156.

Annika CK, Lindén AL (1999) Travel patterns and environmental effects now and in the future. Ecological Economics 30:405-417

Castellani V, Sala S (2010) Sustainable performance index for tourism policy development. Tourism Management 31:871-880

Cheng H, Xu Q, Guo YQ (2020) Spatial heterogeneity and driving factors of tourism carbon emission decoupling in China. East China Economic Management 34:86-93

Gössling S et al (2004) The eco-efficiency of tourism. Ecological Economics 54:417-434

Hoekstra R, Jeroen CJM (2003) Comparing structural decomposition analysis and index. Energy Economics 25:39-64

$\mathrm{Hu} \mathrm{LN}, \mathrm{Hu} \mathrm{HY}$ (2019) Research on the relationship between tourism carbon emissions and economic growth in Tibet based on decoupling theory. Journal of Tibet University (Social Sciences Edition) $34: 185-192+208$

Huang GQ, Wang ZL, Shi PF, Zhou Y (2021) Measurement and spatial differentiation of tourism carbon emission decoupling effect in the Yellow River Basin. China Soft Science 82-93

Huang HP, Qiao XZ, Zhang J (2019) Spatial-temporal evolution of tourism carbon emissions in the Yangtze River Economic Belt. Guizhou Social Sciences 143-152.

Kuo NW, Chen PH (2009) Quantifying energy use, carbon dioxide emission, and other environmental loads from island tourism based on a life cycle assessment approach. Journal of Cleaner Production 17:1324-1330

Lisaba EBF, Lopez NSA (2021) Spatiotemporal comparison of drivers to $\mathrm{CO}_{2}$ emissions in ASEAN: A decomposition study. Sustainability 13:6183-6183

Liu J, Ding D, Tong Y, Ma Y (2019) Research on ecological efficiency of tourism industry in China based on carbon emission accounting. Acta Ecologica Sinica 39:1979-1992

Schafer A, Victor DG (1999) Global passenger travel: implications for carbon dioxide emissions. Energy 24:657-679

Shi PH, Wu P (2011) Preliminary estimation of energy consumption and $\mathrm{CO}_{2}$ emissions in China's tourism industry. Acta Geographica Sinica 66:235-243

Sun YH, Yang GC (2020) Decomposition of influencing factors and decoupling effect of carbon emissions from tourism industry in China. China Environmental Science 40:5531-5539

Tang Z (2015) Calculation of tourism carbon emission and its decoupling analysis with economic growth. Statistics \& Decision 117-120

Tian H, Ding CA (2018) Spatial and temporal differences of regional tourism carbon emissions: A case study of Shandong Province. Journal of Beijing Institute of Technology (Social Science Edition) 20:45-54

Wang K, Xia LH, Chen QC, Liu HL (2018) Carbon emission efficiency of the tourism industry in China based on spatial cluster analysis. Research of Environmental Sciences 31:419-427

Wang K, Yang YP, Zhang SW, Gan C, Liu HL (2019) Spatial correlation between tourism industry agglomeration and carbon emissions in China. Resources Science 41:362-371

Wei YX, Sun GN, Ma LJ (2012) Preliminary Estimation of tourism transportation carbon emission and regional differences in China. Journal of Shaanxi Normal University (Natural Science Edition) 40:76-84 
Weng GM, Li CH, Pan Y, Li JP (2021) Study on the decoupling effect and influencing factors of carbon emission from the tourism industry in China. Geography and Geo-Information Science 37:114-120

Xie YF, Zhao Y (2012) Study on $\mathrm{CO}_{2}$ emission measurement of tourism energy consumption in Yangtze River Delta. Geographical Research 31:429-438

Zha JP, Tan T, Qian XB, Zhao QQ, Yang XJ (2018) Carbon emission and its driving factors in China's tourism industry. Systems Engineering 36:23-36

Zhao XC, Teng J, Tan SJ (2018) Carbon emission measurement and GRA correlation analysis of tourism industry in Hunan Province based on input-output method. World Regional Studies 27:164-174 